\title{
A Biochemical Study to Estimate Malonaldehyde and Ceruloplasmin Oxidase Activity As Parameters Express Oxidation - Antioxidation Balance for Patients with Acute Hepatitis Virus Type C
}

\author{
Rasha Hasan Jasim \\ Chemistry Department-College of Education for Girls-University of Kufa-Iraq \\ dr.rashahussainee@yahoo.com
}

\section{ABSTRACT}

Oxygen free radicals play an important role in the pathogenesis of tissue damage in many pathological conditions, including liver diseases. Aim of the present study focused on the investigation the possible relationship between serum malondialdehyde level, an index of lipid peroxidation, and ceruloplasmin levels, as protective agent against lipid peroxidation, in hepatitis $C$ virus. A group of 31 hepatitis virus type $C$ patients enrolled in the study, while; control group consisted of 25 healthy subjects. In the present study, total proteins $(\mathrm{g} / \mathrm{L})$, malondialdehyde $(\mu \mathrm{M})$, ceruloplasmin oxidase activity $(\mathrm{U} / \mathrm{L})$ and ceruloplasmin concentration $(\mathrm{g} / \mathrm{L})$ were measured in sera samples of patients with hepatitis $C$ virus as well as in the healthy controls.

Keywords: lipid peroxidation; malondialdehyde; ceruloplasmin.

\section{Council for Innovative Research}

Peer Review Research Publishing System

\section{Journal: INTERNATIONAL JOURNAL OF COMPUTERS \& TECHNOLOGY}

Vol 12, No.5

\section{editor@cirworld.com}




\section{INTRODUCTION}

Acute viral hepatitis is one of the most common infectious diseases[1], while hepatitis C virus (HCV) is the most baleful form of acute viral hepatitis in many parts of the world [2 ], viral hepatitis is also a major health problem in Iraq. The most important causes of spreading the disease are low levels of socioeconomical status and poor hygiene conditions, particularly in countryside [3]. Hepatitis $\mathrm{C}$ mostly occurs in the context of community-wide epidemics during which infection is transmitted from person to person by the fecal-oral route[4].

Epidemically of HCV may habit to hypothesis that HCV is one of the main causative agents of chronic viral hepatitis. Chronic hepatitis $\mathrm{C}$ can progress to cirrhosis and eventually to hepatocellular carcinoma over a period of 20 to 30 years [5]. The mechanisms which explain how HCV causes cell damage are not well understood, but symphoniouslly with the fact that liver is the central organ in the metabolism processes [6], one of the mechanisms including immunological liver damage, direct cytotoxicity mediated by different viral product and inductions of oxidative stress have been suggested as playing a pathogenic role in this infection, It has been suggested that HCV may cause oxidative stress in infected cell $[7,8]$.

Oxidative stress is defined as an imbalance between pro-oxidant and antioxidant mechanisms in our body, the balance being tilted in favor of the former, It has been unequivocally implicated in the pathogenesis and pathophysiology of many diseases [9]. Oxidative stress is associated with the disturbance of hepatocyte biochemistry and generation of ROS (reactive oxygen species), when the antioxidant defenses are critically lowered [10].

These ROS can damage cells by causing lipid peroxidation, and oxidative damage of DNA and proteins, and by depleting ATP stores. Prime targets of peroxidation by ROS are polyunsaturated fatty acids (PUFA) in membrane lipids. In the presence of metals (such as $\mathrm{Fe}^{3+}, \mathrm{Cu}^{2+}$ ), $\mathrm{O}^{2 .-}$ can react with $\mathrm{H}_{2} \mathrm{O}^{2}$ to generate a hydroxyl radical than become even more reactive and cytototoxic than $\mathrm{O}^{2--}$ or $\mathrm{H}_{2} \mathrm{O}_{2}$ [8]. PUFA is degraded by free radicals to form malondialdehyde (MDA). The level of MDA in serum serves as a marker of cellular damage due to free radicals. Cells have multiple mechanisms to remove free radicals and thereby minimize tissue injury. Antioxidants such as enzymes, like: superoxide dismutase (SOD) and Ceruloplasmin (Cp), catalase (like: glutathione "GSH" ), and nutritional antioxidants(E and C vitamins) trap free radicals and act as free radical scavenging systems [11-13].

Aim of the present study focused on the investigation the possible relationship between serum malondialdehyde level, an index of lipid peroxidation, and ceruloplasmin levels, as protective agents against lipid peroxidation, in acute hepatitis $\mathrm{C}$ virus cases.

\section{MATERIALS AND METHODS}

\section{Individuals of the Study}

The study group comprised 31 patients with newly diagnosed hepatitis $C$ virus, between the age of 23-67 years who were admitted consecutively to the Liver and Digestive Tract Center of Al-Sader Medical City in Najaf, Iraq, between November 2010 and June 2011. All patients were enrolled in the study before receiving the course of drugs. The patients group consisted of 17 females and 14 males and their range age was 44 years. The control group comprised 25 healthy individuals that included 12 females and 13 males aged between 19-62 (range of 43), the ratio of male to female was shown in Figure 1.
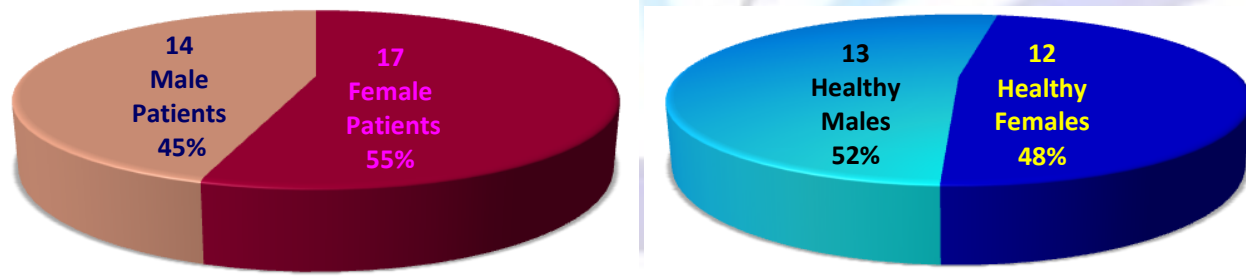

Fig. 1: Gender Distribution of The Study Groups' Individuals

All sera were collected in the morning after fasting 10 hour feature of the subjects in the present study are shown in the table 1. The healthy volunteers were selected on the basis of no alcoholic and smoking habits, without history of viral hepatitis, routing clinical check up during the entire period of research. Patients and control subjects residing in the same geographical area, and they were in the same socioeconomic status and similar diet habits. Patients with chronic hepatitis $\mathrm{C}$ diagnosed based on clinical, biochemical, histological and virological evidence in the same medical city. Blood samples were taken from subjects in accordance with standard procedure, $5 \mathrm{ml}$ of blood was collected from vein and protected in evacuated tubes without anticoagulation agents.

\section{Determination of Total Serum Proteins Levels}

A total serum protein was estimated using Biuret method [14]. Biuret reagent supplied by the Manufacturing Company in a container contains $100 \mathrm{ml}$, that consist of sodium hydroxide $(100 \mathrm{mM})$, sodium-potassium tartrate $(16 \mathrm{mM})$, potassium iodide $(15 \mathrm{mM})$, and cupric sulfate $(6 \mathrm{mM})$. The bovine serum albumin was used as a standard protein. The procedure 
included mixing of $50 \mu \mathrm{l}$ serum or standard with $2.5 \mathrm{ml}$ Biuret reagent, then the mixture was incubated at room temperature for 30 minutes, and the absorbance was measured at $540 \mathrm{~nm}$.

\section{Measurement of Serum Malondialdehyde Level}

Malondialdehyde level is measured by the thiobarbituric acid-reacting substances (TBARS) assay [15]. Abridgment, $150 \mu \mathrm{l}$ of the serum sample was mixed with $1 \mathrm{ml}$ of trichloro acetic acid (TCA) (17.5\%) and $1 \mathrm{ml}$ of thiobarbituric acid (0.6\%). Using the vortex, the final mixture was mix, the reaction mixture was then heated at $100^{\circ} \mathrm{C}$ for 15 minutes in the water bath. After the mixture was cooled with tap water, it was extracted with $1 \mathrm{ml}$ TCA $(70 \%)$, the mixture was stand for 20 minutes at $25^{\circ} \mathrm{C}$, and centrifuged at $3000 \mathrm{xg}$ for 15 minutes. The organic phase was measured by use of a spectrophotometer with a wavelength of $534 \mathrm{~nm}$.

\section{Determination of Ceruloplasmin Oxidase activity}

The activity of ceruloplasmin oxidase was determined in serum using the modified Rice method [16]. The procedure included two glass tubes, test $(A)$ and blank $(B), 1 \mathrm{ml}$ of substrate buffer was added to each tube, then incubated at $37^{\circ} \mathrm{C}$ for $5 \mathrm{~min}$. A $100 \mu \mathrm{l}$ of serum sample was added to tube $A$ then incubated at $37^{\circ} \mathrm{C}$ for $15 \mathrm{~min}$. A volume of $3 \mathrm{ml}$ of cold working inhibition solution was added to all of A and B tubes; at last $100 \mu$ l of deionized water was added to tube B. The absorbance was measured at $\lambda=540 \mathrm{~nm}$.

\section{Reagents}

Preparation of Substrate Buffer: Two gram of p-phenylenediamine was dissolved in the smallest volume of absolute ethanol, then filtered through double filter paper (Whitman number 1). Gently and gradually, concentrated hydrochloric acid was added. The pink precipitate was filtered and washed with methanol, then the product salt ( $p$-phenylenediamine$2 \mathrm{HCl}$ ) was dried at $70^{\circ} \mathrm{C}$. To purification of $\mathrm{p}$-phenylenediamine- $2 \mathrm{HCl}$, the salt was dissolved in a minimum volume of hot water $\left(60^{\circ} \mathrm{C}\right)$, charcoal was added and left for $5 \mathrm{~min}$, and then the mixture was filtered while hot. The purified salt was cold and precipitated from the filtrate by the addition of cold acetone until the turbidity was appeared (for the perfect results, all these step must be done in the ice bath). The mixture was refrigerated for several hours, filtered off the crystals, then it

was dried in the dark in a vacuum desiccators over anhydrous calcium. To prepare substrate buffer, $0.1 \mathrm{~g}$ of crystal $\mathrm{p}$ phenylenediamine- $2 \mathrm{HCl}$ was dissolved in $100 \mathrm{ml}$ of acetate buffer $(0.4 \mathrm{M}, \mathrm{pH} 5.2$, containing $0.4 \mu \mathrm{M}$ EDTA)

Working Inhibition Solution: This solution was prepared by diluting $3 \mathrm{ml}$ of stock inhibition solution $(0.1 \mathrm{M}$ of sodium azide and $0.5 \mathrm{M}$ of sodium chloride) to $100 \mathrm{ml}$ with deionized water, stored at $4^{\circ} \mathrm{C}$, and used cold [17].

\section{Ceruloplasmin Oxidase Activity = The absorbance of $A-B$ tubes $\times 349.04$}

Ceruloplasmin oxidase concentration was determined by measuring the absorbance of $A$ and $B$ tubes at wavelength $=605$ $\mathrm{nm}$.

\section{Ceruloplasmin oxidase concentration $=$ The absorbance of A-B tubes $\times 87.5$.}

\section{Determination of Serum Copper and Iron Levels}

The levels of serum copper and iron were determined by flame atomic absorption spectrophotometry (GBC-933plus).

\section{Statistical Analysis}

The findings were expressed as the mean \pm standard deviation (S.D.). The data were analyzed with Student's independent $\boldsymbol{t}$ test. All statistical analyses were performed with the program Statistical Package for the Social Science (SPSS for Windows, Version 19.0). Pearson's correlation was applied to determined the relations among the laboratory parameters of the present study, significance was determined regression. A $p$-value of $<0.01$ was accepted as statistically significant.

\section{RESULTS AND DISCUSSION}

In the current study, total proteins, malondialdehyde $(\mu \mathrm{M})$, ceruloplasmin oxidase activity $(\mathrm{U} / \mathrm{L})$ and ceruloplasmin concentration $(\mathrm{g} / \mathrm{L})$ were measured in sera samples of patients with acute hepatitis $C$ virus as well as in the healthy controls. Table 1 , shows that no significant variation $(p=0.064)$ of total serum proteins' levels in patients with hepatitis $C$ virus when compared with those of healthy individuals. On the other hand, the statistical evaluation failed to exhibit significant variation $(p<0.001)$ for serum malondialdehyde when patients of hepatitis $C$ virus were compared with those of healthy controls. With same manner, when the comparison was carried out for hepatitis $C$ virus patients and control group, highly significant variations were found for ceruloplasmin oxidase activity and ceruloplasmin concentration $(p<0.000$ and $p<0.001$ for ceruloplasmin oxidase activity and ceruloplasmin concentration; respectively). Statistical analysis demonstrated a significant $(p<0.001)$ variation of copper levels in hepatitis $C$ virus patient group when compared with those in healthy individuals group. The same outcomes, but with reverse manner; the present study recorded elevation in iron levels in hepatitis C virus patients group comparison to controls group, the lowest copper levels and highest iron levels were observed in oldest patients. 
Table 1: Levels (gIL) of TSP, $(\mu \mathrm{M})$ of MAD, (U/L) of Ceruloplasmin Oxidase Activity, and (gIL) of Ceruloplasmin Concentration in Patient of Hepatitis $C$ Virus and control subjects (Mean $\pm S . D$.

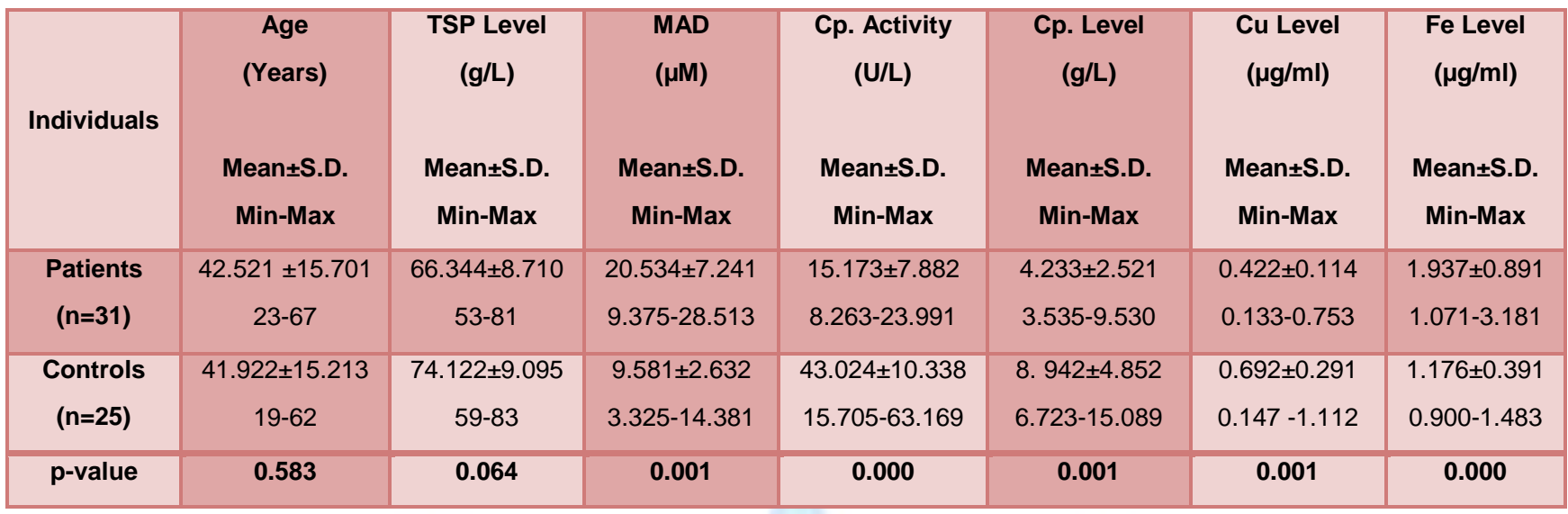

In order to find the possible relation between the oxidation and antioxidation processes through the infection with $\mathrm{C}$ virus of hepatitis, the correlation between malondialdehyde as a profile to the peroxidation process, and ceruloplasmin enzyme (ceruloplasmin oxidase activity) as an agent of antioxidation was studied.

As shown in Figure 2 A, the statistical analysis sucssed to illustrate a stronge negative correlation $(r=-0.813$ at $p<0.000)$ of malodialehyde levels to celoplasmin oxidase activity in sera of pateints, while no such correlation was observed when the compasion carried out in healthy control group (Figure 2 B).

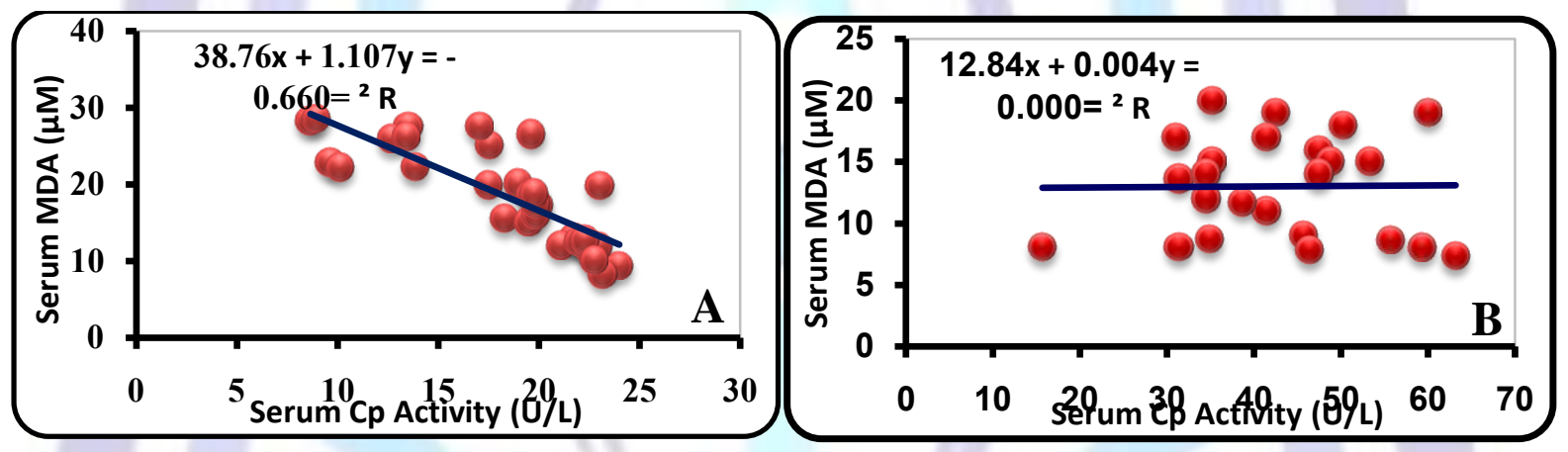

Fig. 2: Correlation of Serum Malondialdehyde to the Ceruloplasmin Oxidase Activity in A: Patients of Hepatitis C Virus, and B: Healthy Individuals

With the same manner, a significant negative correlation $(r=0.731$ at $p<0.001)$ between levels of serum malonaldehyde and ceruloplasmin concentration in patients group, as shown in Figure $\mathbf{3} \mathbf{A}$; on the other hand, the healthy individuals group failed to illustrate same results to those in patients group when the correlation between serum malonaldehyde levels and ceruloplasmin concentration was carried out (Figure 3 B).
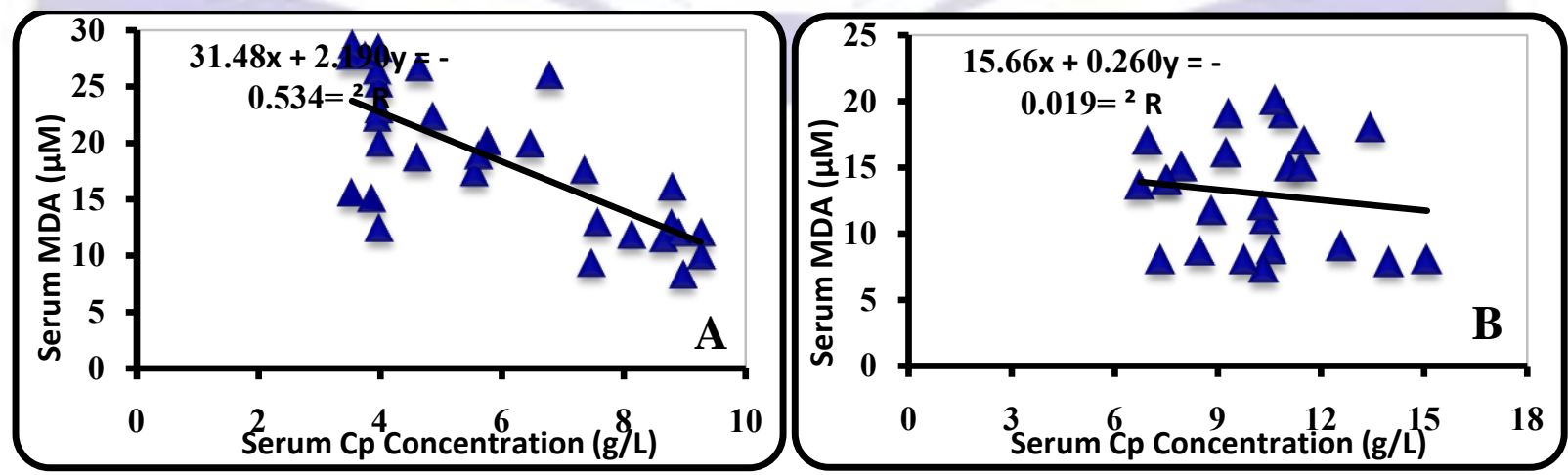

Fig. 3: Correlation Of Serum Malondialdehyde To The Ceruloplasmin Concentration In A: Patients of Hepatitis C Virus, and B: Healthy Individuals

Results of hepatitis $C$ infection parameters which evaluated in the current study, largely depends upon the patient's age at infection and immune status as well as the level of hepatitis $C$ replication. According to the previous studies, normally; total serum proteins level decrease with the age progression; as well as this alteration (increase or decrease) in the protein 
levels was recorded in numerous diseases [18-22]. The result of current study agreed with these findings, where the decreases in the total serum proteins' levels were proportion to the individuals' age (patients and controls), in addition to that the lowest proteins levels were recorded in sera of elderly individuals.

Oxidative damage by oxygen free radicals such as superoxide anions are known to be one of the factors involved in the mechanisms of diseases[23]. During immune activation by viral entities, neutrophils and others cells produce ROS as a mechanism of signal amplification for protection [24]. ROS have also been implicated in a number of hepatic pathologies in exacerbating liver diseases[25], however, the oxidant production associated with immune reactions against viral hepatitis may lead to the formation of hepatocellular carcinoma, but unfortunately, approximately $10-40 \%$ of the patients with chronic HVC treat with the modern therapeutic models maintain the rate of sustained virologic response, therefore; detection of HVC infection and the effective advancement in the antiviral treatments against chronic HVC is necessary [26].

In previous study (personality work in our laboratory from 2010-2012) [22, 25], it showed a progressive rise of malondialdehyde level in serum samples for individuals (patients and healthy) with age. This relationship was highly significant. In the present work, there was a significant negative correlation between serum malondialdehyde level and the age progression (data not shown); this result agreed with the previous findings. On the other hand; malonaldehyde level in sera of patients was elevated $(100 \%$ of cases) than those in sera of healthy individuals; according to this observation the lipid peroxidation status occurred in acute and chronic of infection with HCV, when compared this results with the previous study that deal with sera of patients suffered infection with hepatitis virus type $B$, this study showed lipid peroxidation status didn't occurred in the primary stage of infection with hepatitis virus type B. This comparison illustrates important finding, we can exploit oxidative stress parameter (MDA) in differentiation between hepatitis virus $B$ and $C$ types, to suggest the suitable therapy. This result is agreed with several studies that measured malonaldehyde level as a reflex for lipid peroxidation in numerous diseases [27, 28], while it disagreed with other studies, especially those with liver diseases [25, 29].

Ceruloplasmin is a blue alpha-2 glycoprotein with a molecular weight of $132,000 \mathrm{u}$, It binds $90-95 \%$ of blood plasma copper, has 6-7 Cu ions per molecule, and exhibits ferroxidase activity (an iron oxidase), amine oxidase activity, superoxidase activity, as well as it is involved in Cu transport and homeostasis [30].

The symptoms of many diseases that is characterized by low levels of ceruloplasmin with subsequent copper deposition in various tissues [31]. Results of present study agreed with these studies. In addition, ceruloplasmin is an acute phase reactant, whose concentration increases in inflammation, infection, and trauma, for these properties it is known as an antioxidant. This fact boost the observations of the current work which explained the decreases in Cp activity and concentration in HCV serum to the liver cell damage which causes countermarch in liver functions, then drop in synthesis of many proteins, ceruloplasmin may one of them.

Concurrent study designed in order to investigate the roles and alterations of ceruloplasmin in acute and chronic HCV and compare its outcome with previous study that carried out on the chronic HBV samples.

For the propose of arrive to integral understanding about the ceruloplasmin in HCV case, because copper and iron are linked to the ceruloplasmin [32,33], their levels were determined. Results of the current study illustrated that decrease of copper level in serum of patients with hepatitis virus type $\mathrm{C}$ comparison to healthy controls, adverse result was found at the levels of iron determined. Highlight on the results of copper and iron levels in the patients' sera illustrate that the decrease of copper concentration can be explained as a reflex to the decrease in the ceruloplasmin oxide activity and ceruloplasmin concentration as antioxidant agent in $\mathrm{HCV}$, while, the literatures recorded that raises of the iron levels can be refer to the damage of liver cells [34,35], these information support the hypothesis of the present work "liver cells may damage during different HCV infection stages".

In order to prove the hypothesis of liver cells damage during the prim and advanced infection periods with hepatitis virus $\mathrm{C}$ type, the relationship of the malondialdehyde levels to ceruloplasmin oxidase activity, and ceruloplasmin concentration was carried out. The study outcome showed there are significant relation between these parameters; for that, we can conclude that a decrease in the ceruloplasmin oxide activity and ceruloplasmin concentration are reflex to arise in the lipid peroxidant products and an ambulance in the oxidation - antioxidation status.

\section{REFERENCES}

(1) Mustafa C, Semiha D, Fahri B, Hüseyin Ç, Fatma C, and Nihat M. [2006]: Relationship Between Antioxidant Capacity And Oxidative Stress In Children With Acute Hepatitis A. World Journal of Gastroenterology. 12(38): 6212-6215.

(2) Fujinaga H, Tsutsumi T, Yotsuyanagi H, Moriya K, And Koike K. [2011]: Hepatocarcinogenesis In Hepatitis C: HCV Shrewdly Exacerbates Oxidative Stress By Modulating Both Production And Scavenging Of Reactive Oxygen Species. Oncology. 81(1):11-17.

(3) Saravanamuttu G I, Samreen M J, Ramsay M, Jonathan G.[2007]: International Public Health Repository for Hepatitis C. Nucleic Acid Research. 35(2): 367-370.

(4) Albert J C and Deborah K F.[2012]: Diagnosis And Treatment Of Autoimmune Hepatitis. Hematology. 36(2):479497. 
(5) Ulrich S. [2012]: Diagnosis, Prognosis and Therapy of Hepatocellular Carcinoma.in heamatology. Flying Publisher.UK.

(6) Ghorbani G A, Alavian S M, and Ghadimi H R. [2008]: Long Term Effect of One or Two Doses of Hepatitis C Vaccine in Adult after Five Years. Pakistan Journal of Biological Sciences. 11(4): 660-663.

(7) Haimin C, Xiaojun Y, Peng Z, and Jing L. [2006]: Antioxidant Activity And Hepatoprotective Potential Of AgaroOligosaccharides In Vitro And In Vivo. Nutrition Journal. 5(3): 1-12.

(8) Görenek L, Acar A, Aydın A, Eyigun C P, Çetinkaya A, Eken A, and Sayal A. [2006]: Oxidative Stress And Antioxidant Defense In Patients With Chronic Hepatitis C Patients Before And After Pegylated Interferon Alfa-2b Plus Ribavirin Therapy. Journal of Translational Medicine. 4(25): 1-6.

(9) Sumit B, Mukul P A, Dwivedi S, and Banerjee BD. [2008]: Monitoring Oxidative Stress Across Worsening Child Pugh Class Of Cirrhosis. Indian Journal of Medical Science. 62(11): 444-451.

(10) Mehmet K, Seyithan T, Cemil S, Omer Y, Fatih A, and Metin K. [2004]: Oxidative Stress and Enzymatic Antioxidant Status in Patients with Nonalcoholic Steatohepatitis. Annals of Clinical and Laboratory Science. 34(1): 57-62.

(11) Nikam S, NikamP, Ahaley S K. [2009]: Role of Free Radical and Antioxidant Imbalance in Pathogenesis of Parkinson's Disease. Biomedical Research. 20 (1): 55-58.

(12) Sahu S, Abraham R, Vedavallir R, and Daniel M. [2009]: Study of Lipid Profile, Lipid Peroxidation, and Vitamin E in Pregnancy Induced Hypertension. Indian Journal of Physiology Pharmacology. 53 (4): 365-369.

(13) Moreno-Otero R and Trapero-Marugán M. [2010]: Hepatoprotective Effects of Antioxidants in Chronic Hepatitis C. World Journal of Gastroenterol.16(15): 1937-1938

(14) Plummer A. [1971]: An Introduction to Practical Biochemistry. $1^{\text {st }}$ Edition. Mcgraw Hill. Book Company. London. U $\mathrm{K}$.

(15) Yagi K. [1982]: Assay for Lipid Peroxide Level and Its Clinical Significance. In: Yagi K Editor Lipid Peroxides in Biology and Medicine, New York. p233-242.

(16) Rice E W. [1962]: Ceruloplasmin Assay in Serum: Standardization of Ceruloplasmin Activity in Terms of International Enzyme Unit "Standard Methods of Clinical Chemistry". $4^{\text {th }}$ Eddition, Siligson D., New York, Academic press.

(17) Daoud R M. [2008]: Study of Some Biochemical Changes in Serum \& Saliva of Patients with Oral Epithelial Tumors. Baghdad University, College of Science, Chemistry Department. Treatise.

(18) Jasim R H. [2009]: Isolation, Purification, and Partial Characterization of Human Lectins from Patients of Kidney Tumors. Baghdad University, College of Science for Women, Chemistry Department. Treatise.

(19) Al-Faham R. [2002]: A Biochemical Study of Serum Sialic Acid and Lectins Activity as Tumor Markers for Gastrointestinal Tract Cancers. University of Kufa, College of Education, Chemistry Department. Thesis.

(20) Porter G T, Pou A M, Quinn F B, \& Ryan M W. [2003]: Nutritional Considerations for Head and Neck Cancer Patients. Grand Rounds Presentation, UTMB, Department of Otolaryngology.

(21) Raymond R W. [2007]: Biochemistry of Cancer. In: Cancer Biology. Section 1.p 108-120.

(22) Jasim R H. [2011]: Serum Malondialdehyde And Lipid Profile Levels Of Young Patients "Haven't A Family History Of Hypertension": A New Study For Cases In The Civic Society. Pakistan Journal Of Chemistry.1(3): 120-125.

(23) Harliansyah A H, Noor A M, Wan Z, and Yasmin A M. [2005]: Effects of Zingiber officinale on Superoxide Dismutase, Glutathione Peroxidase, Catalase, Glutathione and Malondialdehyde Content in HepG2 Cell Line. Malaysian Journal of Biochemistry and Molecular Biology. 11, 36-41.

(24) Vera G V, Goran G, Senijo P, Antonio S, Ana-Marija D, Dubravka F, Maja P. [2012]: Assessment of cytogenetic damage and oxidative stress in personnel occupationally exposed to the pulsed microwave radiation of marine radar equipment. International Journal of Hygiene and Environmental Health. 38(2): 1438-1449.

(25) Jasim R H. [2011]:Evaluation of Oxidative-Antioxidative Balance in Serum of Patients With Non Acute Hepatitis Virus Type B. Under publishing (Participated in the 2011 International Conference on Chemistry and Chemical Process - ICCCP 2011)

(26) Ko W, Guo C, Yeh M, Lin L, Hsu G W, Chen P, Luo M, and Lin C. [2005]: Blood Micronutrient, Oxidative Stress, and Viral Load in Patients with Chronic Hepatitis C. World Journal of Gastroenterology. 11(30):4697-4702.

(27) Janaia A V and Suprapaneni K M. [2010]: Antioxidant Vitamins And Enzymes Status In Patients With Alcoholic Liver Disease. Journal of Clinical and Diagnostic Research. 4(4): 2742-2747. 
(28) Aksoy H, Koruk M, and Akçay F. [2003]:The Relationship Between Serum Malondialdehyde and Ceruloplasmin in Chronic Liver Disease. Turkish Journal of Biochemistry. 28 (2): 32-34.

(29) McGrath L, Mc Gleenon B, Brennan S, McColl D, Mcllroy S, and Passmore A. [2001]: Increased Oxidative Stress in Alzheimer's Disease as Assessed with 4- Hydroxynonenal but not Malondialdehyde. Q J Med. 94: 485-490.

(30) Viorica L A, William H R, and Kirk L. [2009]: Ceruloplasmin levels in human sera from various diseases and their correlation with patient's age and gender. Health. 1(2),104-110.

(31) Merle U, Weiss K H, Eisenbach C, Tuma S, Ferenci P, and Stremmel W. [2010]: Truncating Mutations in the Wilson Disease Gene ATP7B are Associated with Very Low Serum Ceruloplasmin Oxidase Activity and An Early Onset of Wilson Disease. BMC Gastroenterology. 10(8): 2-6.

(32) Brewer G J, Kanzer S H, Zimmerman E A, Celmins D F, Heckman S M.[2010]: Copper and Ceruloplasmin Abnormalities in Alzheimer's Disease. American Journal of Alzheimer's Disease. 25 (6): 490-497.

(33) Patel B N, Dunn R J, Jeong S Y, Zhu Q, Julien J, and David S. [2002]: Ceruloplasmin Regulates Iron Levels in the CNS and Prevents Free Radical Injury. The Journal of Neuroscience. 22(15): 6578-6586.

(34) Aigner E and Datez C. [2008]: Iron Perturbations in Human Non-Alcoholic Fatty Liver Disease (NAFLD): Clinical Relevance and Molecular Mechanisms. Hepatitis Monthly. 8(3): 213-220.

(35) Bush A I. [2010]: Iron-Export Ferroxidase Activity of $\beta$-Amyloid Precursor Protein Is Inhibited by Zinc in Alzheimer's Disease. Cell Journal. 142(6): 857-867. 